\title{
PENGARUH BRAND AUTHENTICITY TERHADAP BRAND ATTACHMENT (STUDI KASUS PADA SEPATU OLAHRAGA ADIDAS)
}

\author{
Erwin Saputra \\ Program Studi Magister Manajemen Universitas Tarumanagara \\ erwin.saputraaa@yahoo.com
}

\begin{abstract}
Adidas is one of the most famous brands of sports shoes in the world after Nike. This can be seen from the sales data of Adidas' sports shoes which were ranked second in 2017. Even though the sales of Adidas' sports shoes increased compared to 2016, Adidas' sales were still far below Nike's. Adidas can utilize the brand authenticity that they have to increase their consumer's brand attachment, so it can increase their sales. This study used a questionnaire method distributed to 192 respondents in Jabodetabek who had used Adidas' sport shoes and then processed the data using SPSS. From this study it can be concluded that the brand authenticity significantly and positively influences the brand attachment of Adidas sports shoes users. In addition, it was also found that brand experience can positively moderate the influence of brand authenticity on brand attachment from Adidas sports shoes users.
\end{abstract}

Abstrak : Adidas merupakan salah satu merek sepatu olahraga yang paling terkenal di dunia setelah Nike. Hal ini dapat dilihat dari data penjualan sepatu olahraga Adidas yang menduduki peringkat kedua pada tahun 2017. Meskipun penjualan sepatu olahraga Adidas mengalami kenaikan dibanding tahun 2016, namun penjualannya masih jauh di bawah Nike. Salah satu cara bagi Adidas untuk meningkatkan penjualannya adalah dengan memanfaatkan brand authenticity yang mereka punyai untuk meningkatkan brand attachment konsumennya. Penelitian ini menggunakan metode kuesioner yang disebarkan kepada 192 responden di Jabodetabek yang pernah menggunakan sepatu olahraga Adidas dan selanjutnya pengolahan data menggunakan bantuan software SPSS. Dari penelitian ini dapat disimpulkan bahwa brand authenticity secara signifikan berpengaruh positif terhadap brand attachment dari pengguna sepatu olahraga Adidas. Selain itu, juga ditemukan bahwa brand experience dapat memoderasi secara positif pengaruh brand authenticity terhadap brand attachment dari pengguna sepatu olahraga Adidas.

Keywords : Brand Authenticity, Brand Experience, Brand Attachment

\section{PENDAHULUAN}

Adidas merupakan sebuah perusahaan yang memproduksi berbagai macam peralatan olahraga, salah satunya adalah sepatu olahraga. Persaingan di industri sepatu olahraga, secara umum hanya dikuasai oleh dua perusahaan, yaitu Adidas dan Nike. Hal ini dapat dilihat dari data penjualan pada tahun 2016 dan 2017, dimana pada tahun 2016 Nike mancatatkan penjualan sebesar $\$ 19,9$ b dan meningkat pada tahun 2017 menjadi sebesar $\$ 21,1 \mathrm{~b}$. Sementara itu Adidas pada tahun 2016 berhasil mencatatkan penjualan sebesar $\$ 10,7 \mathrm{~b}$ dan pada tahun 2017 meningkat menjadi $\$ 14,9$ b. Penjualan keduanya jauh melebihi para pesaingnya di industri sepatu olahraga, seperti Asics, Puma, ataupun Under Armour. Jika kita melihat data penjualan dari Adidas sebelumnya, dapat dilihat bahwa Adidas mengalami kenaikan penjualan yang cukup besar pada tahun 2017, yaitu sekitar \$4,2b. Meskipun mengalami kenaikan, tetapi penjualan dari Adidas masih jauh tertinggal jika bandingkan dengan Nike. 
Salah satu cara yang dapat dilakukan Adidas untuk meningkatkan penjualannya adalah dengan memunculkan brand attachment pada para penggunanya agar tercipta suatu ikatan emosional antara konsumen dengan Adidas. Hal ini tentunya akan sangat menguntungkan karena dapat membuat konsumen tersebut memiliki loyalitas dan dapat mempromosikan Adidas kepada orang-orang di sekitarnya sehingga penjualannya dapat meningkat. Untuk memunculkan brand attachment tersebut, Adidas dapat memanfaatkan brand authenticity yang telah dimilikinya. Adidas yang telah berdiri selama lebih dari 60 tahun, tentunya memiliki sebuah sejarah panjang, prinsip-prinsip yang telah menjadi ciri khas, serta memiliki kualitas yang sudah tidak diragukan lagi oleh konsumen. Hal ini juga didukung oleh penelitian yang dilakukan oleh Cohn \& Wolfe (2017), dimana Adidas menempati peringkat keenam di dunia sebagai merek yang paling autentik, sedangkan di Indonesia sendiri menempati peringkat ketujuh.

Selain itu, Adidas juga harus terus mempertahankan dan meningkatkan kualitas dari sepatu olahraganya agar dapat memberikan pengalaman yang positif bagi konsumen. Pengalaman positif yang dirasakan oleh konsumen saat menggunakan sepatu olahraga Adidas diharapkan dapat memperkuat pengaruh dari brand authenticity terhadap brand attachment dari pengguna sepatu olahraga Adidas.

\section{TELAAH KEPUSTAKAAN}

American Marketing Assocation (AMA) mendefinisikan merek sebagai nama, istilah, tanda, lambang, atau desain, atau kombinasinya, yang dimaksudkan untuk mengidentifikasikan barang atau jasa dari satu penjual atau kelompok penjual dan mendiferensiasikan produk atau jasa dari para pesaing (Kotler, 2009). Akan tetapi pada saat ini merek bukan lagi hanya dianggap sebagai suatu nama atau logo yang membedakan produk suatu perusahaan dengan produk pesaing yang sejenis. Merek dapat dianggap sebagai modal dalam menghadapi pesaingan, hal ini dikarenakan merek memiliki suatu keunikan tersendiri yang tidak dapat ditiru oleh perusahaan pesaing. Hal ini didukung dengan pernyatan Temporal \& Lee (2002) yang mengungkapkan beberapa alasan merek dianggap sebagai hal yang penting oleh konsumen, yaitu merek memberikan pilihan, merek memudahkan keputusan, merek memberi jaminan kualitas, merek memberikan pencegahan resiko, dan merek memberikan alat untuk mengekspresikan diri.

Pengertian brand authenticity menurut Coary (2013) adalah keaslian suatu produk dan prinsip-prinsipnya. Brand authenticity juga seringkali dikaitkan dengan keunikan, tradisi, dan budaya. Brand authenticity dapat menjadi hal yang penting bagi suatu perusahaan dalam memasarkan produknya karena hal tersebut dapat menjadi pertimbangan konsumen saat ingin membeli suatu produk. Konsumen sering kali menggunakan nilai autentik ini untuk membedakan produk yang asli atau imitasi (Bruner, 1994). Menurut Coary (2013) terdapat tiga aspek yang menentukan nilai keautentikan dari suatu merek, yaitu lamanya merek tersebut didirikan, komitmen suatu merek terhadap produk aslinya melalui suatu tradisi yang tidak terputus, dan suatu merek yang secara terus-menerus melakukan hal yang tulus melalui interaksi antara karyawan atau perusahaan dengan konsumen dan meremehkan kepentingan komersial yang dapat membawa keuntungan.

Brand attachment adalah suatu konsep yang dikembangkan dari disiplin ilmu psikologi yang dikenal dengan theory attachment. Teori ini dikembangkan oleh Bowlby (1969) yang menyatakan bahwa attachment adalah suatu ikatan emosional yang mendalam dan kuat yang menghubungkan seseorang dengan orang lain melintasi ruang dan waktu. Teori ini menjelaskan bahwa keterikatan (attachment) tidak harus bersifat timbal balik. Sementara itu Park, MacInnis, Priester, Eisingerich, \& Iacobucci (2010) mendefinisikan 
brand attachment sebagai kekuatan ikatan yang menghubungkan merek dengan diri seseorang. Priester, MacInnis, \& Park (2006) menyatakan semakin kuat keterkaitan konsumen terhadap suatu merek, maka produk dari merek tersebut dapat dijual dengan harga yang lebih tinggi dimana hal tersebut memberikan keuntungan terhadap perusahaan.

Brakus, Schmitt, \& Zarantonello (2009) mendefinisikan brand experience sebagai suatu sensasi, perasaan, kognisi, dan respon tingkah laku konsumen yang ditimbulkan karena adanya keterkaitan konsumen terhadap suatu merek, yang dapat diakibatkan dari desain atau identitas merek, kemasan, komunikasi, dan lingkungan. Brand experience ini bersifat subjektif, sehingga pengalaman seseorang dalam menggunakan suatu brand dapat berbeda dengan pengalaman orang lain. Beberapa brand experience dapat terjadi secara spontan dan hanya dirasakan dalam waktu yang singkat, sementara ada brand experience yang terjadi karena disengaja dan pengalaman tersebut dirasakan dalam waktu yang lama (Brakus et al., 2009). Terdapat lima dasar penting dalam brand experience, yaitu memberikan pengalaman kepada pelanggan sesuai dengan brand promise, membuat brand tersebut menjadi "people brands", secara agresif berusaha mendekatkan diri dengan konsumen, menyadari nilai keautentikan dari brand mereka, dan menciptakan suatu cara baru dalam berinteraksi dengan konsumen sehingga dapat menimbulkan suatu pengalaman yang unik bagi konsumen.

\section{Kerangka Pemikiran}

Berdasarkan penelitian terdahulu yang dilakukan oleh Assiouras et al. (2014) ditemukan bahwa terdapat hubungan positif antara brand authenticity dengan brand attachment dari konsumen makanan ELMA dan Ouzo Plomari. Hasil yang serupa juga ditemukan oleh Guevremont \& Grohmann (2014) yang menyatakan bahwa brand authenticity memiliki pengaruh positif terhadap brand attachment. Sementara itu pada penelitian yang dilakukan oleh Kowalczyk \& Pounders (2016) ditemukan bahwa celebrity authenticity memiliki pengaruh yang positif terhadap emotional attachment. Berdasarkan penelitian-penelitian tersebut maka dapat diambil hipotesis sebagai berikut.

\section{H1 : Brand authenticity berpengaruh positif terhadap brand attachment.}

Pada penelitian terdahulu belum ditemukan terdapat penelitian yang menguji bagaimana peran dari brand experience sebagai variabel moderasi pada hubungan antara brand authenticity dan brand attachment. Akan tetapi pada penelitian sebelumnya telah diketahui bahwa brand experience memiliki pengaruh positif terhadap brand attachment (Chinomona, 2013 ; Ramaseshan \& Stein, 2014). Atas dasar penelitian tersebut maka diambil hipotesis sebagai berikut.

$\mathrm{H} 2$ : Brand experience memoderasi pengaruh brand authenticity pada brand attachment.

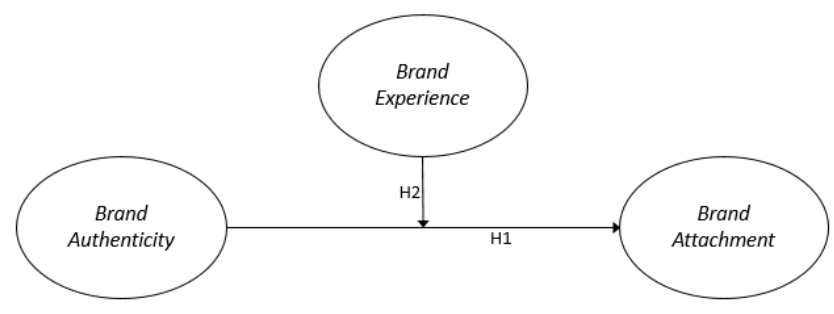




\section{METODOLOGI PENELITIAN}

Sampel yang digunakan pada penelitian ini diambil secara random dari populasi yang diteliti, yaitu masyarakat yang pernah menggunakan sepatu olahraga Adidas dan tinggal di daerah Jabodetabek. Pengambilan sampel ini bertujuan untuk mempersingkat waktu yang diperlukan dan menghemat biaya penelitian ini. Proses pengambilan data sampel pada penelitian ini menggunakan metode kuesioner yang akan dilakukan secara online dengan teknik non probability sampling dan metode purposive sampling. Pada penelitian ini didapatkan kuesioner sebanyak 250, namun hanya 192 kuesioner yang dapat diolah karena terdapat 48 responden yang tidak pernah menggunakan sepatu olahraga Adidas namun mengisi kuesioner dan 10 responden yang pernah menggunakan sepatu olahraga Adidas namun bertempat tinggal di luar Jabodetabek. Pertanyaan yang terdapat pada kuesioner tersebut secara umum terbagi menjadi dua bagian, yaitu mengenai profil dari responden dan mengenai variabel dari penelitian ini.

Berdasarkan kuesioner yang telah diisi dari 192 responden tersebut dapat diketahui 99 responden $(52 \%)$ merupakan laki-laki dan 93 responden (48\%) merupakan perempuan; 169 responden $(88 \%)$ berusia 17-26 tahun, 20 responden $(10 \%)$ berusia $27-36$ tahun, dan 3 responden (2\%) berusia $37-46$ tahun; 3 responden $(2 \%)$ berpendidikan terakhir kurang dari SMA, 39 responden (20\%) berpendidikan terakhir SMA, 8 responden (4\%) berpendidikan terakhir D1-D3, 129 responden (67\%) berpendidikan terakhir S1, dan 13 responden (7\%) berpendidikan terakhir lebih dari S1; 72 responden (37\%) berdomisili di Jakarta, 30 responden (16\%) berdomisili di Bogor, 15 responden (8\%) berdomisili di Depok, 47 responden (24\%) berdomisili di Tangerang, dan 28 responden (15\%) berdomisili di Bekasi; 99 responden $(52 \%)$ merupakan karyawan swasta, 60 responden (31\%) merupakan pelajar atau mahasiswa, 25 responden (13\%) merupakan wiraswasta, dan 8 responden (4\%) memiliki pekerjaan lainnya; 59 responden $(31 \%)$ memiliki rata-rata pengeluaran dalam satu bulan sebesar kurang dari dua juta rupiah, 97 responden (50\%) memiliki rata-rata pengeluaran dalam satu bulan sebesar dua juta rupiah hingga lima juta rupiah, dan 36 responden (19\%) memiliki rata-rata pengeluaran dalam satu bulan sebesar lebih dari lima juta rupiah.

\section{HASIL DAN PEMBAHASAN}

Hasil dari kuesioner tersebut selanjutnya akan dilakukan pengujian validitas dan realibilitas. Pada pengujian validitas didapatkan bahwa seluruh item pertanyaan pada kuesioner memiliki R Hitung (nilai pearson correlation) yang lebih besar dibandingkan R Tabel sehingga seluruh item pertanyaan pada kuesioner ini dapat dinyatakan valid. Sementara untuk pengujian realibilitas, ketiga variabel pada penelitian ini memiliki nilai yang lebih besar dari 0,60 sehingga ketiga variabel tersebut dapat dikatakan reliabel (Tabel 1).

Tabel 1. Pengujian Realibilitas

\begin{tabular}{|c|c|}
\hline Variabel & Cronbach's Alpha \\
\hline Brand Authenticity & 0,972 \\
\hline Brand Experience & 0,959 \\
\hline Brand Attachment & 0,965 \\
\hline
\end{tabular}

Setelah mengetahui bahwa hasil dari kuesioner tersebut valid dan reliabel, maka selanjutnya akan dilakukan pengujian terhadap hipotesis penelitian ini yang menggunakan metode Model 1 Hayes dengan menggunakan program SPSS. Pada pengujian tersebut dapat diketahui bahwa H1 diterima yang berarti brand authenticity berpengaruh positif terhadap brand 
attachment $(\beta=0,1228)$. Sementara untuk $\mathrm{H} 2$ juga diterima yang berarti brand experience memoderasi secara positif pada pengaruh brand authenticity terhadap brand attachment $(\beta=0,03)$. Hal tersebut dapat dilihat dari kedua nilai $p$-value yang kurang dari 0,05 dan nilai LLCI serta ULCI yang semuanya positif (Gambar 1). Dari hasil yang didapatkan tersebut maka didapatkan persamaan sebagai berikut.

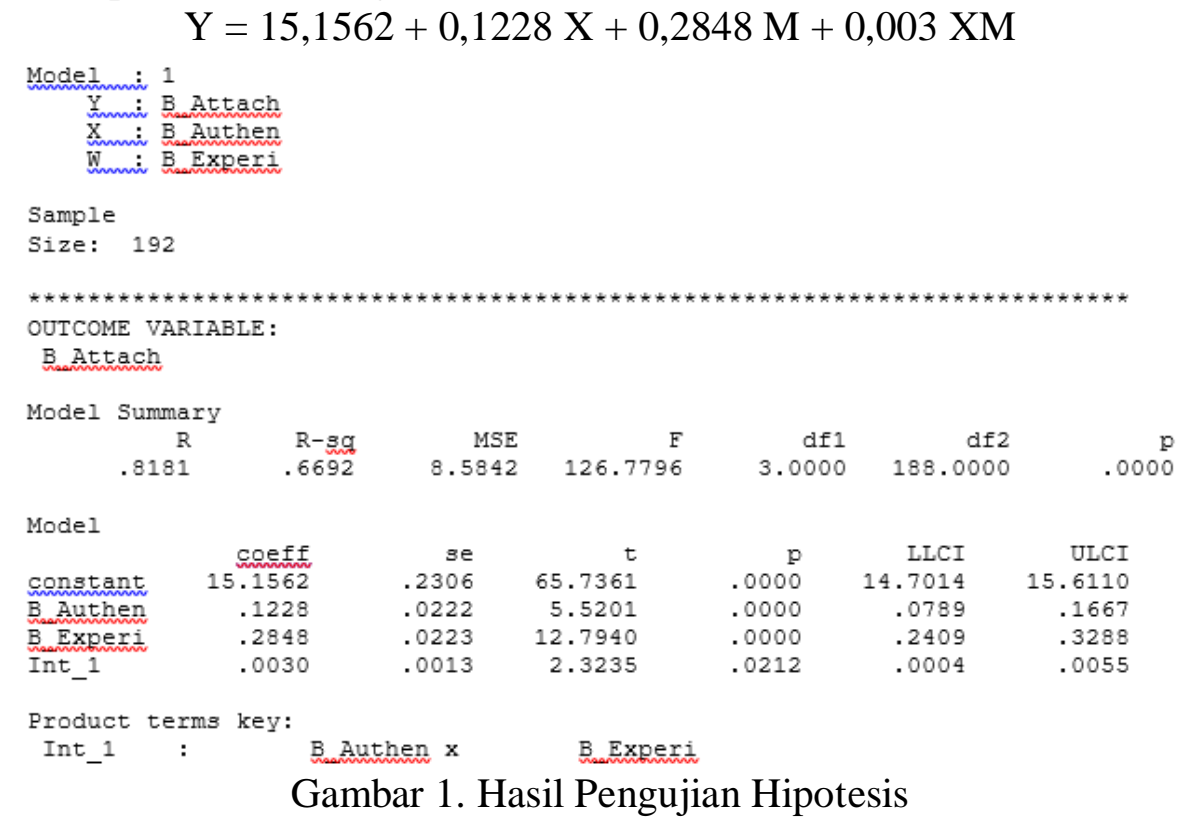

Peran brand experience sebagai variabel moderasi pada penelitian ini juga akan disimulasikan pada tiga kondisi (low, medium, dan high) untuk mengetahui apakah variabel brand experience dapat memoderasi pada kondisi tersebut. Dari hasil yang didapatkan, diketahui bahwa brand experience memoderasi secara positif pada pengaruh brand authenticity terhadap brand attachment baik saat kondisi low, medium, maupun high (Gambar 2).

$$
\begin{aligned}
& \text { Conditional effects of the focal predictor at values of the moderator(s): } \\
& \begin{array}{rrrrrrr}
\text { Bopxperi } & \text { Effect } & \text { se } & t & p & \text { LLCI } & \text { ULCI } \\
-11.6553 & .0881 & .0265 & 3.3263 & .0011 & .0359 & .1404 \\
.0000 & .1228 & .0222 & 5.5201 & .0000 & .0789 & .1667 \\
11.6553 & .1574 & .0271 & 5.8181 & .0000 & .1041 & .2108
\end{array}
\end{aligned}
$$

Selanjutnya akan dilihat seberapa besar peran dari brand authenticity dan brand experience terhadap brand attachment dengan menguji model pada berbagai kondisi (low, medium, dan high). Dari hasil pengujian tersebut diketahui bahwa nilai brand attachment akan berada memiliki nilai tertinggi sebesar 20,2663 saat brand authenticity dan brand experience dalam kondisi high (Gambar 3).

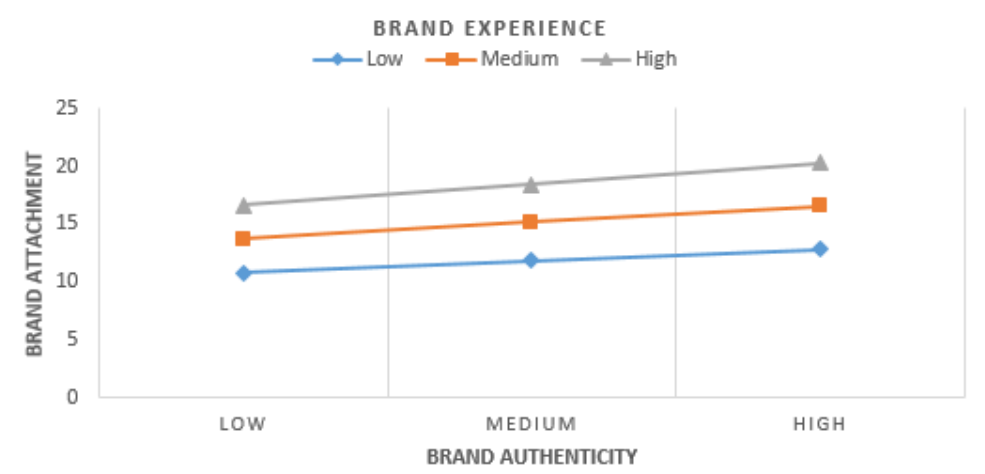

Gambar 3. Pengaruh Brand Authenticity dan Brand Experience 


\section{Diskusi}

Di dalam persaingan industri yang semakin ketat, banyak perusahaan yang mencoba segala cara untuk membuat produk yang disukai oleh konsumen namun dengan sering kali mengabaikan nilai authenticity dari produk mereka tersebut. Hal ini sangat berbahaya bagi perusahaan yang hanya berfokus pada produk yang mereka hasilkan karena menurut Peterson (2005), nilai authenticity merupakan salah satu aspek yang sangat dihargai oleh konsumen dari suatu merek. Hal ini disebabkan dengan tidak banyaknya merek yang memiliki nilai authenticity yang kuat membuat konsumen memiliki keinginan untuk menggunakan merek dengan nilai authenticity yang kuat.

Pada penelitian ini dapat disimpulkan bahwa brand authenticity secara signifikan berpengaruh positif terhadap brand attachment dari konsumen sepatu olahraga Adidas dan hasil tersebut sekaligus memperkuat penemuan yang dihasilkan pada penelitian-penelitan sebelumnya (Assiouras et al., 2014 ; Guevremont \& Grohmann, 2014; Kowalczyk \& Pounder, 2016). Maka dari itu dari penelitian ini dapat disimpulkan bahwa brand authenticity berpengaruh positif terhadap brand attachment dari konsumen sepatu olahraga Adidas di daerah Jabodetabek.

Selain itu pada penelitian ini juga diketahui bahwa brand experience secara positif memoderasi pengaruh brand authenticity terhadap brand attachment. Hal ini menunjukkan bahwa meskipun nilai authenticity yang kuat dari suatu brand dapat membentuk ikatan atau hubungan (attachment) dengan konsumennya, akan lebih baik jika produk tersebut dapat memberikan pengalaman yang positif kepada konsumen. Hal tersebut dapat semakin memperkuat ikatan atau hubungan (attachment) antara suatu merek dengan konsumennya.

Seperti pada penelitiannya lainnya, penelitian ini pun mengalami keterbatasan yang dapat dikembangkan pada penelitian-penelitian selanjutnya. Salah satu keterbatasan pada penelitian ini adalah pada penelitian ini hanya diteliti pada konsumen sepatu olahraga Adidas yang bertempat tinggal di daerah Jabodetabek dikarenakan keterbatas waktu dan dana. Pada penelitian selanjutnya juga dapat diteliti bagaimana pengaruh dari brand authenticity terhadap brand attachment serta peran brand experience sebagai variabel moderasi pada konsumen sepatu olahraga Adidas di seluruh Indonesia maupun di negara lain.

Selain itu, merek yang digunakan pada penelitian ini adalah Adidas sebagai salah satu produsen sepatu olahraga. Pada penelitian selanjutnya juga dapat diteliti pada merek-merek lain yang memiliki nilai authenticity yang tinggi di mata konsumen. Hal ini karena mungkin saja terdapat adanya perbedaan jika penelitian ini menggunakan merek lainnya. Penelitian ini menggunakan variabel brand experience sebagai variabel moderasi. Pada penelitian selanjutnya dapat juga menggunakan variabel moderasi lain untuk menggantikan brand experience ataupun dapat menambahkan variabel moderasi lain selain dari brand experience.

\section{KESIMPULAN}

Pada penelitian ini ditemukan bahwa brand authenticity berpengaruh positif terhadap brand attachment dari konsumen sepatu olahraga Adidas dan brand experience dapat memoderasi secara positif pengaruh brand authenticity terhadap brand attachment tersebut. Hal ini tentunya dapat dimanfaatkan oleh Adidas untuk memperkuat brand attachment dari konsumennya. Perusahaan Adidas harus dapat terus meningkatkan nilai authenticity dari sepatu olahraga Adidas di mata konsumen sehingga dapat tercipta keterikatan antara konsumen dengan sepatu olahraga Adidas. Selain itu perusahaan Adidas harus terus menjaga 
dan meningkatkan kualitas dari sepatu olahraga Adidas sehingga konsumen sepatu olahraga Adidas dapat merasakan pengalaman (experience) yang baik atau positif dan dapat tercipta keterikatan antara konsumen dengan sepatu olahraga Adidas yang lebih kuat.

\section{DAFTAR PUSTAKA}

Assiouras, Ioannis., Liapati, Georgia., Kouletsis, Georgios., Koniordos, Michalis. (2014). The Impact of Brand Authenticity on Brand Attachment in the Food Industry. British Food Journal, 117 (2), 538-552.

Bowlby, John. (1969). Attachment and Loss : Volume 1 Attachment. New York : Penguin Group.

Brakus, J. Josko., Schmitt, Bernd H., Zarantonello, Lia. (2009). Brand Experience: What Is It? How Is It Measured? Does It Affect Loyalty? . Journal of Marketing, 73 (3), 52-68.

Bruner, Edward M. (1994). Abraham Lincoln as Authentic Reproduction: A Critique of Postmodernism. American Anthropologist, 96 (2), 397-415.

Chinomona, Richard. (2013). The Influence Of Brand Experience On Brand Satisfaction, Trust And Attachment In South Africa. International Business \& Economics Research Journal, 12 (10), 1303-1316.

Coary, Sean P. (2013). Scale Construction And Effects Of Brand Authenticity. United States : ProQuest LLC

Guevremont, Amelie., Grohmann, Bianca. (2016). The brand authenticity effect: situational and individual-level moderators. European Journal of Marketing, 50 (3/4), 602-620.

Kotler, Philip. (2009). Manajemen Pemasaran (13 ${ }^{\text {th }}$ ed). Jakarta : Erlangga.

Kowalczyk, Christine M., Pounders, Kathrynn R. (2016). Transforming celebrities through social media: the role of authenticity and emotional attachment. Journal of Product \& Brand Management, 25 (4), 345-356.

Park, C. Whan., MacInnis, Deborah J., Priester, Joseph., Eisingerich, Andreas B., Iacobucci, Dawn. (2010). Brand Attachment and Brand Attitude Strength : Conceptual and Empirical Differentiation of Two Critical Brand Equity Drivers. Journal of Marketing, 74 (6), 1-17.

Priester, Joseph., MacInnis, Deborah J., Park, C. Whan. (2006). Brand Attachment: Constructs, Consequences, and Causes. Foundations and Trends in Marketing®, 1 (3), 191230.

Ramaseshan, B. \& Stein, Alisha. (2014). Connecting the dots between brand experience and brand loyalty: The mediating role of brand personality and brand relationships. Journal of Brand Management, 21 (7/8), 664-683.

Temporal, Paul., Lee, K.C. (2002). Hi-Tech Hi-Touch Branding. Jakarta : Gramedia Pustaka Utama. 
